\title{
GAMBARAN FAKTOR RISIKO DAN KOMPLIKASI PENCABUTAN GIGI DI RSGM PSPDG-FK UNSRAT
}

\author{
${ }^{1}$ Randy Lande \\ ${ }^{2}$ Billy J. Kepel \\ ${ }^{3}$ Krista V. Siagian \\ ${ }^{1}$ Kandidat Skripsi Program Studi Pendidikan Dokter Gigi Fakultas Kedokteran \\ ${ }^{2}$ Bagian Kimia Fakultas Kedokteran Universitas Sam Ratulangi \\ ${ }^{3}$ Program Studi Pendidikan Dokter Gigi Fakultas Kedokteran \\ Universitas Sam Ratulangi \\ Email: randylande@rocketmail.com
}

\begin{abstract}
Tooth extraction is the process of pulling a tooth out from the alveolus since the tooth can not be treated anymore. The risk factors for complicated tooth extraction are systematic diseases, local state of oral cavity, and age of the patient. The complications that might occur in tooth extraction are bleeding, fracture (crown, root, and mandibula), dry socket, swelling, mandibula dislocation, and shock. This study aimed to obtain the risk factors and complications of tooth extraction at RSGM PSPDG-FK Unsrat. This was a descriptive observational study with a cross sectional design. The total population was 76 patients. There were 44 samples obtained by using a consecutive sampling technique. The results showed that the risk factors oftenly found were hypertension $20.45 \%$, age $>60$ years $20.45 \%$, and temporomandibular disorders $6.82 \%$. The highest percentage of tooth extraction complications was fractures $31.82 \%$ meanwhile the lowest percentage was swelling $2.27 \%$. Conclusion: The risk factors that most often found in tooth extraction patients at RSGM PSPDG-FK Unsrat were hypertension and age $>60$ years and the complications that frequently occured was fractures.
\end{abstract}

Keywords: tooth extraction, risk factor, complications of tooth extraction.

\begin{abstract}
Abstrak: Pencabutan gigi adalah proses pengeluaran gigi dari alveolus, dimana pada gigi tersebut sudah tidak dapat dilakukan perawatan lagi. Faktor risiko terjadinya komplikasi pada pencabutan gigi antara lain: penyakit sistemik, keadaan lokal rongga mulut, dan umur pasien. Komplikasi yang mungkin terjadi selama tindakan pencabutan gigi ialah perdarahan, fraktur (mahkota, akar, mandibula), dry socket, pembengkakan, dislokasi mandibula, syok, dan beberapa komplikasi lainnya. Penelitian ini bertujuan untuk mengetahui gambaran faktor risiko dan komplikasi yang terjadi akibat pencabutan gigi di RSGM PSPDG-FK Unsrat. Penelitian ini menggunakan metode deskriptif observasional dengan desain potong lintang. Teknik pengambilan sampel yaitu consecutive sampling. Jumlah populasi sebanyak 76 pasien, dan berdasarkan rumus teknik pengambilan sampel tersebut diperoleh jumlah sampel sebanyak 44 pasien. Hasil penelitian menunjukkan faktor risiko yang dijumpai selama penelitian yaitu berturut-turut hipertensi $20,45 \%$, umur $>60$ tahun $20,45 \%$, dan gangguan pada temporomandibular joint 6,82\%. Komplikasi pencabutan gigi yang tertinggi yaitu fraktur $31,82 \%$ sedangkan komplikasi terendah ialah pembengkakan 2,27\%. Simpulan: Faktor risiko yang paling banyak dijumpai pada pasien pencabutan gigi di RSGM PSPDG-FK Unsrat ialah hipertensi dan umur $>60$ tahun sedangkan komplikasi yang banyak terjadi ialah fraktur.
\end{abstract}

Kata kunci: pencabutan gigi, faktor resiko, komplikasi pencabutan gigi 
Pencabutan gigi adalah suatu proses pengeluaran gigi dari alveolus, dimana pada gigi tersebut sudah tidak dapat dilakukan perawatan lagi. Pencabutan gigi juga merupakan tindakan bedah minor pada bidang kedokteran gigi yang melibatkan jaringan keras dan jaringan lunak pada rongga mulut. ${ }^{1}$ Pencabutan gigi adalah pengeluaran suatu gigi yang utuh atau sisa akar tanpa menyebabkan rasa sakit dan trauma. ${ }^{2}$ Pada tindakan pencabutan gigi harus memerhatikan keadaan lokal maupun keadaan umum penderita dan memastikan penderita dalam keadaan sehat.

Seluruh rencana perawatan pada tindakan pencabutan gigi harus didasari dengan ketelitian dalam memeriksa keadaan umum pasien sebelum melakukan tahap perawatan. Dalam melakukan tindakan pencabutan gigi akan dijumpai beberapa masalah kesehatan yang sama dan terdapat pada masing-masing pasien pencabutan gigi. Hal demikian yang akan menjadi faktor resiko terjadinya komplikasi pencabutan gigi. Beberapa faktor resiko yang biasanya menjadi penyebab komplikasi pencabutan gigi antara lain penyakit sistemik, umur pasien, keadaan akar gigi, dan adanya gangguan pada sendi temporomandibula. $^{3}$

Komplikasi akibat pencabutan gigi dapat terjadi karena berbagai faktor dan bervariasi pula dalam hal yang ditimbulkannya. Komplikasi dapat digolongkan menjadi intraoperatif, segera sesudah pencabutan dan jauh setelah pencabutan. ${ }^{1}$ Komplikasi yang sering ditemui pada pencabutan gigi antara lain perdarahan, pembengkakan, rasa sakit, dry socket, fraktur, dan dislokasi mandibula. ${ }^{2}$

Pengetahuan yang mendalam tentang teknik-teknik pencabutan gigi mutlak diketahui dalam melakukan tindakan pencabutan khususnya dengan jalan pembedahan, agar dapat mencegah atau mengurangi terjadinya efek samping/ komplikasi yang tidak diinginkan. Selain itu, perawatan pasca pembedahan juga merupakan suatu hal yang penting agar prosedur pencabutan gigi yang dilakukan berhasil dengan baik dan sempurna.
Beberapa peneliti telah banyak meneliti mengenai perdarahan dan dry socket yang merupakan komplikasi pencabutan gigi yang sering terjadi. ${ }^{2}$

Berdasarkan data RISKESDAS pada tahun 2013 diperoleh data dari hasil wawancara sebesar 25,9\% penduduk Indonesia mempunai masalah gigi dan mulut dalam 12 bulan terakhir (potential demand). Diantara mereka, terdapat 31,1\% yang menerima perawatan dan pengobatan dari tenaga medis (perawat gigi, dokter gigi atau dokter gigi spesialis), sementara 68,9\% lainnya tidak dilakukan perawatan. Secara keseluruhan kemampuan untuk mendapatkan pelayanan dari tenaga medis gigi/ effectiv Medical Demand (EMD) hanya $8,1 \%$. Provinsi Sulawesi Utara merupakan salah satu provinsi yang mempunyai masalah gigi diatas rata-rata nasional yaitu 31,6\%. ${ }^{4}$ Khusus kota Manado, kasus pencabutan gigi di seluruh puskesmas yang terdapat di 9 kecamatan ialah 2.296 kasus pada tahun 2011. ${ }^{5}$

Pada penelitian di tahun 2013 yang dilakukan di RSGMP drg. Halimah Dg.Sikati FKG UNHAS menunjukkan data prevalensi komplikasi akibat pencabutan gigi sebesar 16,8\% fraktur mahkota, 13,6\% fraktur akar, 4\% dry socket, 1,6\% perdarahan, dan rasa sakit sebesar $1,6 \%{ }^{6}$

Berdasarkan survei awal yang dilakukan pada tanggal 30 Maret hingga 1 April 2015 di RSGM PSPDG-FK UNSRAT menunjukkan angka rata-rata pencabutan gigi pasien dewasa tiap bulannya sebanyak 76 pasien. Total perkunjungan pada bagian Bedah Mulut selama enam bulan terakhir berjumlah 461 pasien dewasa.

Berdasarkan hal tersebut, peneliti tertarik untuk melakukan penelitian mengenai gambaran faktor resiko dan komplikasi pencabutan gigi di RSGM PSPDG FK-UNSRAT.

\section{METODE PENELITIAN}

Penelitian ini bersifat deskriptif observasional dengan desain cross sectional dan dilakukan pada bulan Februari-Agustus 2015. Subjek pada 
penelitian ini ialah semua pasien yang datang berkunjung di bagian bedah mulut RSGM PSPDG-FK UNSRAT dan memenuhi kriteria untuk dijadikan sampel dalam penelitian ini. Metode pengambilan sampel ialah consecuctive sampling dengan jumlah sampel 44 orang.

Instrumen yang digunakan pada penelitian ini ialah lembar pemeriksaan. Data diperoleh melalui pengamatan langsung terhadap subjek penelitian, kemudian data yang didapatkan dituliskan kedalam lembar pemeriksaan atau lembar penelitian. Data yang telah dikumpulkan diolah dan disajikan berdasarkan distribusi frekuensi dalam bentuk tabel kemudian dianalisis secara deskriptif berdasarkan hasil persentase.

\section{HASIL PENELITIAN}

Berdasarkan data dari hasil penelitian yang dilakukan di RSGM PSPDG-FK UNSRAT pada bulan Juni - Juli 2015, diperoleh 44 pasien yang berkunjung pada bagian Bedah Mulut dan memenuhi kriteria inklusi untuk dipilih menjadi sampel dalam penelitian ini.

Sampel pada penelitian ini berjumlah 44 responden dengan karakteristik dikelompokkan berdasarkan jenis kelamin dan umur. Data pada Tabel 1 menunjukkan bahwa jumlah responden yang bersedia menjadi sampel penelitian dan memenuhi kriteria inklusi ialah responden perempuan sebanyak 25 (56\%) dan laki - laki sebanyak 19 responden (44\%).

Tabel 1. Distribusi karakteristik responden berdasarkan jenis kelamin

\begin{tabular}{ccc}
\hline $\begin{array}{c}\text { Jenis } \\
\text { Kelamin }\end{array}$ & $\mathrm{n}$ & $\%$ \\
\hline $\mathrm{L}$ & 19 & 43,18 \\
$\mathrm{P}$ & 25 & 56,82 \\
TOTAL & 44 & 100 \\
\hline
\end{tabular}

Data pada Tabel 2 menunjukkan distribusi sampel berdasarkan umur dan dari 44 sampel penelitian yang memenuhi kriteria inklusi terdapat pasien yang berumur 14 - 60 tahun lebih banyak daripada pasien yang berumur diatas 60 tahun.

Tabel 2. Distribusi karakteristik responden berdasarkan umur

\begin{tabular}{ccc}
\hline Umur (tahun) & $\mathrm{n}$ & $\%$ \\
\hline $14-30$ & 13 & 29,55 \\
$30-60$ & 22 & 50 \\
$>60$ & 9 & 20,45 \\
TOTAL & 44 & 100 \\
\hline
\end{tabular}

Hasil penelitian faktor risiko dan komplikasi pencabutan gigi di RSGM PSPDG-FK UNSRAT untuk periode JuniJuli 2015 disajikan dalam Tabel 3.

Tabel 3.Distribusi faktor resiko terjadinya komplikasi pencabutan gigi

\begin{tabular}{lccccccc}
\hline \multicolumn{1}{c}{ Faktor Resiko } & \multicolumn{2}{c}{ YA } & \multicolumn{2}{c}{ TIDAK } & \multicolumn{2}{c}{ TOTAL } \\
\cline { 2 - 7 } & $\mathrm{n}$ & \multicolumn{2}{c}{$\%$} & $\mathrm{n}$ & $\%$ & $\mathrm{n}$ & $\%$ \\
Hipertensi & 9 & 20,45 & 35 & 79,55 & 44 & 100 \\
Umur>60 tahun & 9 & 20,45 & 35 & 79,55 & 44 & 100 \\
Gangguan & TMJ & 3 & 6,82 & 41 & 93,18 & 44 & 100 \\
(clicking) & & & & & & \\
\hline
\end{tabular}

Data pada Tabel 3 menunjukkan faktor resiko terjadinya komplikasi dalam pencabutan gigi. Berdasarkan data tersebut dapat digambarkan Hipertensi dan umur $>60$ tahun merupakan persentase tertinggi sebanyak 9 kasus, sedangkan faktor resiko yang memiliki persentase terendah adalah gangguan pada TMJ sebanyak 3 kasus.

Data pada Tabel 4 menunjukkan persentase tertinggi komplikasi pencabutan gigi ialah fraktur sebanyak 14 kasus dan persentase terendah ialah pembengkakan 
sebanyak 1 kasus, sedangkan komplikasi berupa dry socket, syok, dislokasi mandibula, alergi obat, dan infeksi tidak terjadi selama penelitian berlangsung.

Tabel 4. Distribusi Komplikasi pencabutan gigi di RSGM PSPDG-FK UNSRAT

\begin{tabular}{ccccccc}
\hline Komplikasi Pencabutan & \multicolumn{2}{c}{ YA } & \multicolumn{2}{c}{ TIDAK } & \multicolumn{2}{c}{ TOTAL } \\
\cline { 2 - 7 } Gigi & $\mathbf{n}$ & $\mathbf{\%}$ & $\mathbf{n}$ & $\mathbf{\%}$ & $\mathbf{n}$ & $\mathbf{\%}$ \\
\hline Fraktur & 14 & 31,82 & 30 & 68,18 & 44 & 100 \\
Perdarahan & 2 & 4,55 & 42 & 95,45 & 44 & 100 \\
Pembengkakan & 1 & 2,27 & 43 & 97,73 & 44 & 100 \\
Dry Socket & 0 & 0 & 44 & 100 & 44 & 100 \\
Syok & 0 & 0 & 44 & 100 & 44 & 100 \\
Dislokasi mandibula & 0 & 0 & 44 & 100 & 44 & 100 \\
Alergi obat & 0 & 0 & 44 & 100 & 44 & 100 \\
Infeksi & 0 & 0 & 44 & 100 & 44 & 100 \\
\hline
\end{tabular}

Tabel 5 menunjukkan bahwa angka kejadian komplikasi yang diakibatkan faktor resiko sangat sedikit. Berdasarkan penelitian ini didapatkan hanya ada 3 kasus komplikasi yang diakibatkan oleh faktor resiko yaitu pada faktor resiko gangguan TMJ dan hipertensi menunjukkan komplikasi fraktur sebanyak 1 kasus, dan pada faktor resiko hipertensi menunjukkan komplikasi perdarahan sebanyak 1 kasus.

Tabel 5. Distribusi faktor resiko dan komplikasi pencabutan gigi

\begin{tabular}{cccc}
\hline Komplikasi Pencabutan & \multicolumn{3}{c}{ Faktor Resiko } \\
\cline { 2 - 4 } Gigi & Hipertensi & $\begin{array}{c}\text { Umur }>\mathbf{6 0} \\
\text { tahun }\end{array}$ & Ganggun TMJ \\
Fraktur & 1 & 0 & 1 \\
Perdarahan & 1 & 0 & 0 \\
Pmbengkakan & 0 & 0 & 0 \\
Dry socket & 0 & 0 & 0 \\
Syok & 0 & 0 & 0 \\
Dislokasi mandibula & 0 & 0 & 0 \\
Alergi obat & 0 & 0 & 0 \\
Infeksi & 0 & 0 & 0 \\
\hline
\end{tabular}

\section{BAHASAN}

Berdasarkan hasil penelitian yang dilakukan di RSGM PSPDG - FK UNSRAT pada bulan Juni -Juli 2015 prevalensi tertinggi dari faktor resiko yang dapat menyebabkan terjadinya komplikasi pada tindakan pencabutan gigi di RSGM PSPDG - FK UNSRAT pada bulan Juni Juli 2015 ialah hipertensi dan usia >60 tahun sebanyak 20,45\% atau 9 kasus (Tabel 2) kemudian prevalensi terendah ialah gangguan pada TMJ yaitu 6,82\% atau sebanyak 3 kasus dari 44 pasien yang menjadi sampel penelitian. Prevalensi tertinggi dari komplikasi yang terjadi pada tindakan pencabutan gigi yaitu fraktur sebanyak 31,82\% (Tabel 4) masing-masing fraktur mahkota sebanyak 23\% atau 10 kasus dan fraktur akar sebanyak $9 \%$ atau 4 kasus. Penelitian ini, sejalan dengan penelitian sebelumnya yang dilakukan Eka Priana pada tahun 2013 di Makassar menemukan prevalensi komplikasi pencabutan gigi yang tertinggi ialah fraktur 
mahkota dan fraktur akar. ${ }^{5}$ Menurut penelitian Eka angka kejadian komplikasi fraktur mahkota yaitu 16,8\% atau sebanyak 21 kasus dari 215 sampel penelitian, sedangkan angka kejadian fraktur akar sebanyak 13,6\% atau sebanyak 17 kasus. Pada penelitian ini juga menggambarkan prevalensi komplikasi pencabutan gigi yang terbilang sedikit terjadi di RSGM PSPDG- FK UNSRAT yaitu perdarahan 4,54\% atau sebanyak 2 kasus, pembengkakan $2,27 \%$ atau sebanyak 1 kasus (Tabel 4). Pada Tabel 4 diatas menunjukkan bahwa komplikasi pencabutan gigi berupa dry socket, syok, dislokasi mandibula, alergi obat, dan infeksi tidak terjadi selama penelitian. Prevalensi dry socket pada penelitian ini berbeda dengan penelitian yang dilakukan oleh Baratollah Shaban pada tahun 2014 yang menunjukkan angka kejadian dry socket sebanyak $27 \%$ atau 11 kasus dari 41 responden. $^{7}$

Keadaan gigi yang rapuh, adanya karies yang besar, adanya tambalan pada gigi yang dicabut, dan juga tekanan yang tidak terkontrol dapat menunjang terjadinya fraktur pada mahkota gigi pada saat dilakukan pencabutan gigi. Selain itu, faktor operator juga sangat berperan dalam terjadinya kasus fraktur mahkota gigi. Operator biasanya kurang tepat mengaplikasikan tang pada gigi, misalnya operator menempatkan tang tepat pada mahkota bukan pada akar gigi. Terkadang juga gigi yang akan dicabut sangat kuat dikarenakan adanya granuloma, akar gigi yang terlalu panjang/ besar menyebabkan operator sukar untuk mencabut gigi. Terburu - buru biasanya merupakan penyebab dari semua kesalahan, yang sebenarnya dapat dihindari bila operator bekerja sesuai dengan standar operasional yang telah ditetapkan. Pemberian tekanan berlebihan tidak dianjurkan karena dapat menyebabkan fraktur pada mahkota gigi. ${ }^{8}$

Berdasarkan pengamatan pada saat penelitian ini ditemukan beberapa faktor yang menyebabkan fraktur mahkota menjadi komplikasi yang tertinggi, yaitu posisi operator yang tidak tepat dalam melakukan pencabutan gigi dapat menyulitkan operator sehingga kemungkinan terjadinya fraktur mahkota gigi sangat besar. Keadaan gigi yang sangat kuat juga menjadi salah satu penyebab utama terjadinya fraktur mahkota pada gigi. Selain itu operator terkadang mencabut gigi saat gigi tersebut belum diluksasi secara sempurna.

Kasus fraktur pada akar gigi dapat disebabkan varisasi anatomi akar gigi dapat menyulitkan tindakan pencabutan gigi, seperti akar gigi yang bengkok, ukuran akar gigi yang terlalu besar, hypersementosis, adanya granuloma pada ujung akar gigi, dan juga keadaan akar gigi yang sudah rapuh dikarenakan karies. Akar yang mengalami dilaserasi atau akar yang dirawat endodontik sering mengharuskan dilakukannya perubahan pada rencana pencabutan, biasanya dimulai dari prosedur pencabutan menggunakan tang (closed method) sampai melakukan pembukaan flap (open method). Apabila sesudah dilakukan pencabutan menggunakan tang dengan tekanan terkontrol dan tidak terjadi luksasi dan dilatasi alveolus, ini menunjukkan perlunya dilakukan pembedahan. $^{1}$

Perdarahan yang terjadi dalam penelitian ini sangat sedikit (Tabel 4). Perdarahan dapat terjadi karena trauma berlebihan pada jaringan lunak pasien, pencabutan yang dilakukan pada siang hari yang menyebabkan dengan mudah terjadinya perdarahan. Perdarahan yang terjadi pada penelitian ini adalah jenis perdarahan primer dimana perdarahan yang terjadi saat terputusnya pembuluh darah dikarenakan kecelakaan atau operasi. ${ }^{9}$ Perdarahan ini berlangsung 4-5 menit.

Pembengkakan juga terjadi dalam penelitian ini akan tetapi hanya dijumpai pada 1 kasus (Tabel 4). Banyak faktor yang bisa menjadi penyebab terjadinya pembengkakan, misalnya karena infeksi bakteri, dan luka yang terlalu banyak pada daerah bekas pencabutan. 


\section{SIMPULAN}

Prevalensi faktor risiko terjadinya komplikasi pada pencabutan gigi ialah hipertensi 20,45\%, umur $>60$ tahun $20,45 \%$, dan gangguan pada temporomandibular joint 6,82\%. Prevalensi komplikasi pencabutan gigi selama penelitian yaitu fraktur sebesar 31,82\%, perdarahan sebesar 4,54\%, dan pembengkakan sebesar 2,27\%.

\section{SARAN}

Bagi para mahasiswa kepaniteraan perlu mengetahui faktor-faktor risiko terjadinya komplikasi saat pencabutan gigi, hal ini bisa dilakukan dengan memperdalam materi atau bahkan bisa diamati pada saat melakukan tindakan pencabutan.

Komplikasi pencabutan gigi dapat dicegah dengan mengetahui terlebih dahulu faktor-faktor yang bisa menyebabkan terjadinya komplikasi selama atau bahkan sesudah dilakukan pencabutan gigi. Selain itu operator wajib mengetahui dan melakukan tindakan pencabutan gigi sesuai dengan standar prosedur yang sudah ditetapkan.

\section{UCAPAN TERIMAKASIH}

Ucapan terima kasih disampaikan pada drg. Christy Mintjelungan, MKes, drg.P.S Anindhita, SpOrto, dan pada semua pihak yang baik secara langsung maupun tidak langsung telah menumbuhkan ide atau gagasan dalam pemikiran penulis sehingga dapat menyelesaikan artikel ini.

\section{DAFTAR PUSTAKA}

1. Gordon PW. Buku Ajar Praktis Bedah Mulut (4th ed). Jakarta: EGC, 2013; p. 36-44, 93-100.

2. Chandra HM. Buku Petunjuk Praktis Pencabutan Gigi (1st ed). Makassar: Sagung Seto, 2014.

3. Howe L Geoffrey. Minor Oral Surgery (2nd ed.). London: John Wright \& Sons, 1971; p. 41-5.

4. Riset Kesehatan Dasar (RISKESDAS) Nasional 2013 p. 110-3. [cited Februari 2015]. Available from: http://www.depkes.go.id/gigi.pdf.

5. Riset Kesehatan Dasar (RISKESDAS) [Online] 2007. [cited Februari 2015]. Available from: http://www.litbang.depkes.go.id.simn as.4/day.2/gigi:pdf.

6. PrianaE. Prevalensi Komplikasi Pencabutan Gigi di RSGMP Drg. Halimah, dg Sikati FKG Unhas. Makassar: Universitas Hasanuddin; 2013.

7. Shaban B, Azimi HR, Naderi H, Janani A, Zarrabi MJ, Nejat AH. Effect of 0,2 Chlorheksidin Gel on Frequency of Dry Socket Following Mandibular Third Molar Surgery: A DoubleBlind Clinical Trial. Mashhad University. 2014;3:175-9.

8. Riawan L. Penanggulangan Komplikasi Pencabutan Gigi. Bandung;2002.

9. Moya MJ. Manajemen Luka (1st ed). Jakarta: Penerbit Buku Kedokteran EGC, 2004; p. 222-5. 